\title{
Impact of COVID-19 on the Number of Surgical Cases at a Tertiary Care Hospital in Karachi, Pakistan
} \author{
and Summaya Saeed ${ }^{2}$ \\ ${ }^{1}$ Fazaia Ruth Pfau Medical College, Pakistan Air Force Hospital, Faisal, Karachi, Pakistan \\ ${ }^{2}$ Dr Ruth. K.M. Pfau Civil Hospital Karachi, Pakistan \\ *Corresponding author: Amara Zafar, Dr Ruth. K.M. Pfau Civil Hospital Karachi, Pakistan
}

Ammara Salam ${ }^{1}$, Maria Ahmed ${ }^{2}$, Amara Zafar ${ }^{2 *}$, Sana Shahid ${ }^{2}$, Maheen Rana ${ }^{2}$, Ibrahim Zahid ${ }^{2}$

\begin{abstract}
ARTICLE INFO
Received: 蔧 April 19, 2021

Published: 幽 May 06, 2021

Citation: Ammara S, Maria A, Amara Z, Sana S, Maheen R, et al., Impact of COVID-19 on the Number of Surgical Cases at a Tertiary Care Hospital in Karachi, Pakistan. Biomed J Sci \& Tech Res 35(4)-2021. BJSTR. MS.ID.005727.
\end{abstract}

Keywords: COVID-19; Pandemics; General Surgery

Abbreviations: SPSS: Statistical Package for the Social Sciences; COVID-19: Coronavirus Disease 2019; PHEIC: Public Health Emergency of International Concern; WHO: World Health Organization; SMBB: Shaheed Mohtarma Benazir Bhutto; IRB: Institutional Review Board; DUHS: Dow University of Health Sciences; HIMS: Hospital Information Management System; NHS: National Health Service; PPE: Personal Protective Equipment

\section{ABSTRACT}

Objective: The aim of this study was to find out the decline in the number of surgical cases done during this pandemic, and the effect on number of oncological procedures performed.

\section{Design: Observational study.}

Place and Duration of Study: The study was conducted at Dr. Ruth K. M. Pfau Civil Hospital Karachi, for ten months from October 2019 till July 2020.

Methodology: First five months were taken as pre-Covid state (October 2019-February 2020) and next five as the Covid state (March 2020- July 2020). Data was analyzed using IBM Statistical Package for the Social Sciences (SPSS) version 23.0 and tables were constructed using Microsoft Excel® 2016. Results for quantitative variable were presented as frequencies and percentages. Independent $\mathrm{T}$ test was used to compare the monthly means of pre-Covid and Covid months. The p-value $<0.05$ was considered significant.

Results: The total number of emergency cases performed in these ten months were 2190 out of which 1419 (64.8\%) cases were performed during pre-Covid state and 771 (35.2\%) cases were performed during Covid state. The total number of elective cases performed were 3184 out of which 2750 (86.4\%) cases were performed during preCovid state while 434 (13.6\%) cases were performed during Covid state.

Conclusion: The pandemic has drastically affected the number of surgical cases performed in both elective and emergency theatres. In addition to this the number of oncological procedures performed have also declined significantly. As surgeons, we need to devise ways to address this issue and prevent further backlog.

\section{Introduction}

Coronavirus Disease 2019 (COVID-19) emerged in the Wuhan city of China in December 2019 [1]. With rising number of cases and reported deaths, on $30^{\text {th }}$ January 2020, the World Health Organization (WHO) declared this outbreak as Public Health Emergency of International Concern (PHEIC) [2]. In Pakistan, first case of COVID-19 was confirmed on $26^{\text {th }}$ February 2020 in Karachi, Sindh [3]. Soon after which it was declared as a pandemic by the WHO on $11^{\text {th }}$ March 2020 [4]. The disease has left negative impacts on various sectors of human life and has led to serious socioeconomic implications globally [5]. As the number of cases started to rise, outnumbering the bed capacity of healthcare facilities, it was advised to abandon all elective work at the hospitals. This was done to save the healthcare resources and protect healthcare personnel from unnecessary exposure. On $13^{\text {th }}$ March 2020, The American College of Surgeons issued a guideline recommending that all healthcare facilities shall review all scheduled elective procedures 
with a plan to minimize, postpone or cancel them. This was to be done until the healthcare infrastructure was confident to support any overwhelming critical patient care needs [6]. Likewise, in Pakistan, all sort of elective work (out-patient clinics and elective procedures) were suspended from the mid of March 2020 as Pakistan was also expecting to hit the pandemic peak [2]. The main purpose behind this decision was to decrease the exposure of healthcare workers and save the human and material resources.

Although this proved helpful in combatting the COVID-19 emergency, but in the long run it has left a large impact. Dr Ruth K.M. Pfau Civil Hospital Karachi, which caters thousands of patients every day and offers all sorts of advanced surgical procedures to the patients free of cost was also affected. Hundreds of elective surgical procedures were cancelled, and cancer surgeries were also restricted. In order to estimate the difference in the surgical cases done before the pandemic and during the pandemic, we carefully planned this study. The aim of this study was to find out the decline in the number of surgical cases done during this pandemic, and the effect of the pandemic on number of oncological procedures performed. These numbers are not mere figures but rather depiction of the patient suffering.

\section{Methodology}

An observational study was conducted at Dr Ruth K.M. Pfau Civil Hospital Karachi and Shaheed Mohtarma Benazir Bhutto (SMBB) Accident Emergency and Trauma Centre, Karachi. The study was conducted for a total duration of ten months from October 2019 till July 2020. Ethical approval to conduct this study was taken from Institutional Review Board (IRB) of Dow University of Health Sciences (DUHS). Cases performed from October 2019 to February 2020, were considered as pre-Covid state and from March 2020 till July 2020 as Covid state. All surgeries including elective and emergency procedures, conducted during the study period were included. Data was collected from two sources. For elective surgical procedures, data was collected from Hospital Information Management System (HIMS) record at the Dowite's 87 Operation Theatre Complex. For emergency procedures, data was collected from data maintained in HIMS at SMBB Trauma center theatre. A Table 1.
Performa was filled out for all participants of the study. Data was entered and analyzed using IBM Statistical Package for the Social Sciences (SPSS) version 23.0 (IBM SPSS Statistics for Windows, Armonk, NY) and tables were constructed using Microsoft Excel ${ }^{\circledR}$ 2016 (Microsoft Corp., Redmond, WA). Results for qualitative variables were presented as frequencies and percentages. Chisquare was used to compare the frequencies of pre-Covid and Covid cases. The p-value $<0.05$ was considered significant in all cases.

\section{Results}

(Table 1) shows the demographic characteristics of patients presenting during this 10 -month period. There were more males (71.0\%) than females $(29.0 \%)$ during both pre-covid and covid period and there was no significant difference observed. The mean age of patients was $35.2 \pm 16.2$ years. The total number of emergency cases performed in these ten months (October 2019-July 2020) were 2190 out of which 1419 (64.8\%) cases were performed during Pre-Covid state (October 2019-February 2020) and 771 (35.2\%) cases were performed during Covid state (March 2020July 2020) (Figure 1). The total number of Elective cases performed were 3184 out of which 2750 (86.4\%) cases were performed during Pre-Covid state (October 2019-February 2020) while 434 (13.6\%) cases were performed during Covid state (March 2020July 2020) (Figure 2). (Table 1) Demographics (Table 1) depicts the frequencies and percentages of emergency procedures performed before and during the pandemic, highlighting the major procedures that are performed, which included debridement, appendectomy, laparotomies and incision and drainage procedures. A significant difference was observed between exploratory and traumatic laparotomy and incision and drainage procedure before and during the pandemic $(\mathrm{p}<0.05)$ (Table 2). (Tables $3 \& 4$ ) further elaborate the monthly frequencies and percentages of the emergency surgeries performed for both pre-Covid and Covid state. It was observed that Exploratory Laparotomy was the most common procedure performed among emergency surgeries $(30.6 \%, \mathrm{n}=671)$ followed by Incision and Drainage $(22.7 \%, \mathrm{n}=498)$, Appendectomy $(14.9 \%$, $\mathrm{n}=326)$ and Debridement $(9.4 \%, \mathrm{n}=205)$. Traumatic surgeries were less commonly performed than non-trauma surgeries.

\begin{tabular}{|c|c|c|c|}
\hline Demographics & Pre-COVID & COVID & P value \\
\hline Gender & & & 0.24 \\
\hline Male & $995(70.1 \%)$ & $559(72.5 \%)$ & \\
\hline Female & $424(29.9 \%)$ & $212(27.5 \%)$ & \\
\hline Age (Mean \pm standard deviation)/years & $35.2 \pm 16.6$ & $35.2 \pm 15.4$ & 0.94 \\
\hline
\end{tabular}




\section{Emergency Cases}

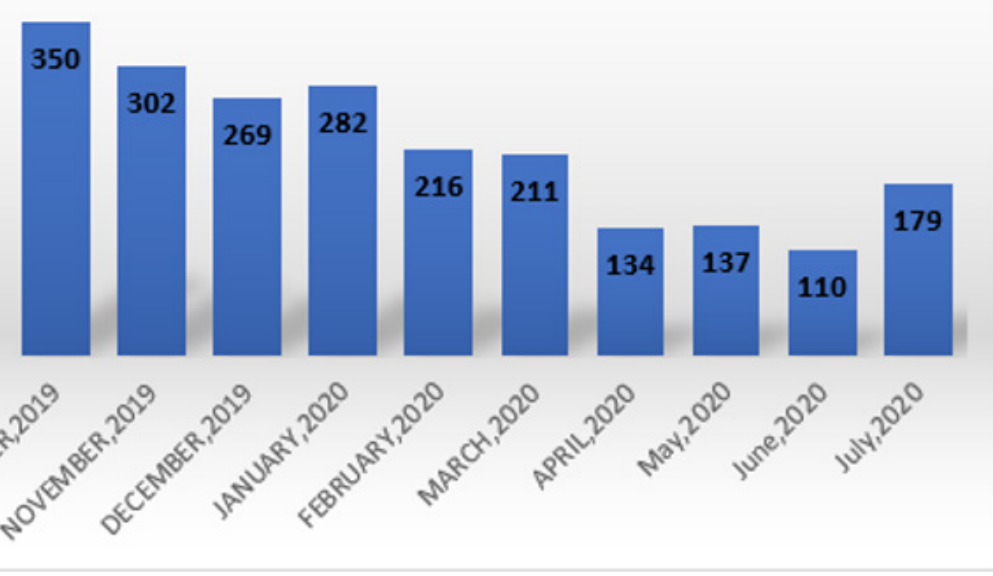

Figure 1: Emergency cases during pre-Covid and Covid state.

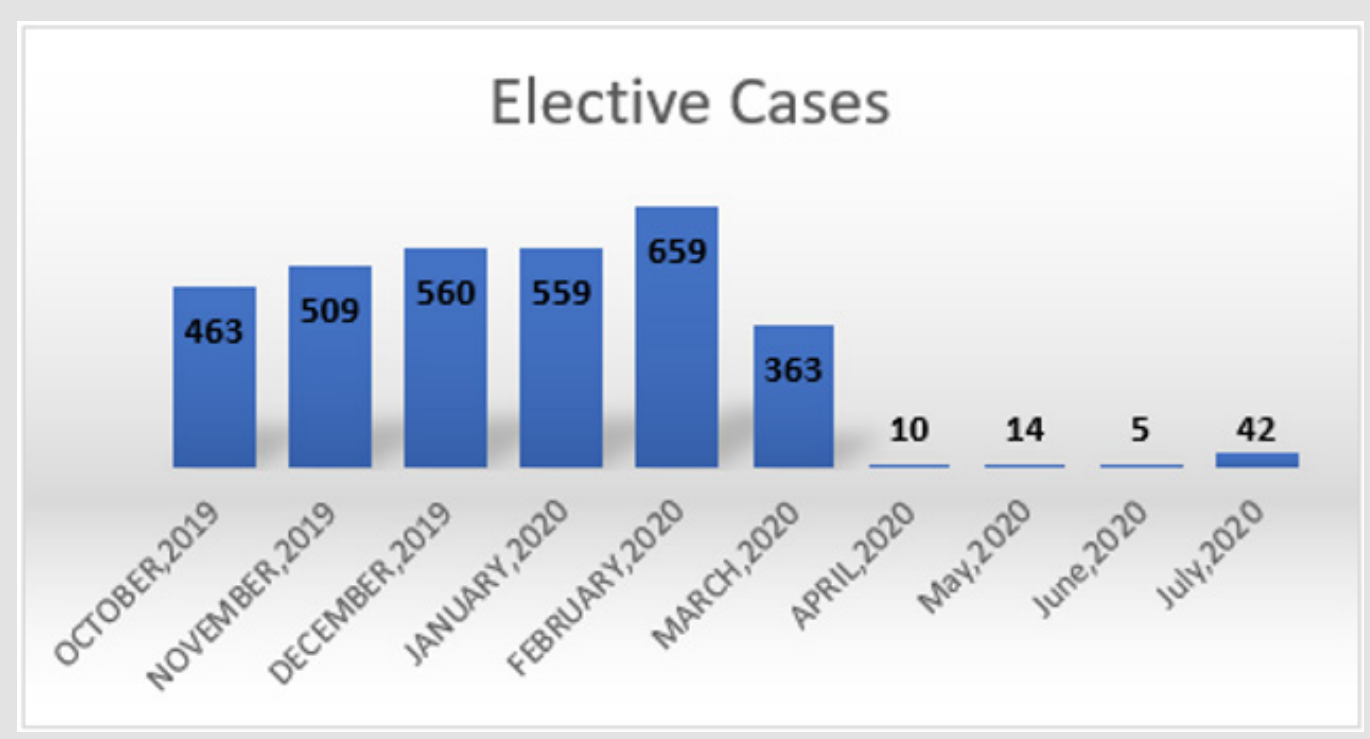

Figure 2: Elective cases during pre-Covid and Covid state.

Table 2: Comparison of monthly frequencies of emergency cases during pre-Covid and Covid period.

\begin{tabular}{|c|c|c|c|c|}
\hline & Pre-covid & CovID & Total & p-value \\
\hline \multirow{2}{*}{ Debridement } & 145 & 60 & 205 & 0.062 \\
\hline \multirow{2}{*}{ Appendectomy } & $10.20 \%$ & $7.80 \%$ & 326 & $0.40 \%$ \\
\hline \multirow{2}{*}{ Exploratory laparotomy } & 216 & 110 & $14.90 \%$ & $<71$ \\
\hline \multirow{2}{*}{ Incision and drainage } & $15.20 \%$ & $14.30 \%$ & $30.60 \%$ & $<0.001^{*}$ \\
\hline \multirow{2}{*}{ Trauma laparotomy } & 398 & 273 & 498 & $0.001^{*}$ \\
\hline \multirow{2}{*}{ Other procedures } & $25.00 \%$ & $143.70 \%$ & 150 & $<0.001^{*}$ \\
\hline
\end{tabular}

Note: *p-value $<0.05$ considered as significant 
Table 3: Monthly frequency of emergency cases during pre-Covid state.

\begin{tabular}{|c|c|c|c|c|c|c|c|}
\hline \multirow[b]{2}{*}{ Month } & \multicolumn{7}{|c|}{ PRE-COVID } \\
\hline & Debridement & Appendectomy & $\begin{array}{l}\text { Exploratory } \\
\text { laparotomy }\end{array}$ & $\begin{array}{l}\text { Incision and } \\
\text { drainage }\end{array}$ & $\begin{array}{c}\text { Trauma } \\
\text { laparotomy }\end{array}$ & Other & Total \\
\hline October & $\begin{array}{c}37 \\
25.50 \% \\
\end{array}$ & $\begin{array}{c}38 \\
17.60 \% \\
\end{array}$ & $\begin{array}{c}104 \\
26.10 \%\end{array}$ & $\begin{array}{c}102 \\
28.70 \%\end{array}$ & $\begin{array}{c}14 \\
18.70 \% \\
\end{array}$ & $\begin{array}{c}55 \\
23.90 \% \\
\end{array}$ & $\begin{array}{c}350 \\
24.70 \% \\
\end{array}$ \\
\hline November & $\begin{array}{c}34 \\
23.40 \%\end{array}$ & $\begin{array}{c}45 \\
20.80 \%\end{array}$ & $\begin{array}{c}88 \\
22.10 \%\end{array}$ & $\begin{array}{c}72 \\
20.30 \%\end{array}$ & $\begin{array}{c}15 \\
20.00 \%\end{array}$ & $\begin{array}{c}48 \\
20.90 \%\end{array}$ & $\begin{array}{c}302 \\
21.30 \%\end{array}$ \\
\hline December & $\begin{array}{c}30 \\
20.70 \%\end{array}$ & $\begin{array}{c}54 \\
25.00 \%\end{array}$ & $\begin{array}{c}65 \\
16.30 \%\end{array}$ & $\begin{array}{c}68 \\
19.20 \%\end{array}$ & $\begin{array}{c}13 \\
17.30 \%\end{array}$ & $\begin{array}{c}39 \\
17.00 \%\end{array}$ & $\begin{array}{c}269 \\
19.00 \%\end{array}$ \\
\hline January & $\begin{array}{c}29 \\
20.00 \%\end{array}$ & $\begin{array}{c}37 \\
17.10 \%\end{array}$ & $\begin{array}{c}78 \\
19.60 \% \\
\end{array}$ & $\begin{array}{c}60 \\
16.90 \%\end{array}$ & $\begin{array}{c}18 \\
24.00 \%\end{array}$ & $\begin{array}{c}60 \\
26.10 \%\end{array}$ & $\begin{array}{c}282 \\
19.90 \%\end{array}$ \\
\hline February & $\begin{array}{c}15 \\
10.30 \%\end{array}$ & $\begin{array}{c}42 \\
19.40 \%\end{array}$ & $\begin{array}{c}63 \\
15.80 \%\end{array}$ & $\begin{array}{c}53 \\
14.90 \%\end{array}$ & $\begin{array}{c}15 \\
20.00 \%\end{array}$ & $\begin{array}{c}28 \\
12.20 \%\end{array}$ & $\begin{array}{c}216 \\
15.20 \%\end{array}$ \\
\hline
\end{tabular}

Table 4: Monthly frequency of emergency cases during Covid state.

\begin{tabular}{|c|c|c|c|c|c|c|c|}
\hline \multirow[b]{2}{*}{ Month } & \multicolumn{7}{|c|}{ DURING COVID } \\
\hline & Debridement & Appendectomy & Exp laparotomy & $\begin{array}{c}\text { Incision and } \\
\text { drainage }\end{array}$ & $\begin{array}{c}\text { Trauma } \\
\text { laparotomy }\end{array}$ & Other & Total \\
\hline March & $\begin{array}{c}19 \\
31.70 \%\end{array}$ & $\begin{array}{c}37 \\
33.60 \%\end{array}$ & $\begin{array}{c}75 \\
27.50 \%\end{array}$ & $\begin{array}{c}41 \\
28.70 \%\end{array}$ & $\begin{array}{c}13 \\
17.30 \%\end{array}$ & $\begin{array}{c}26 \\
23.60 \%\end{array}$ & $\begin{array}{c}211 \\
27.40 \%\end{array}$ \\
\hline April & $\begin{array}{c}7 \\
11.70 \%\end{array}$ & $\begin{array}{c}25 \\
22.70 \%\end{array}$ & $\begin{array}{c}55 \\
20.10 \%\end{array}$ & $\begin{array}{c}20 \\
14.00 \%\end{array}$ & $\begin{array}{c}9 \\
12.00 \%\end{array}$ & $\begin{array}{c}18 \\
16.40 \%\end{array}$ & $\begin{array}{c}134 \\
17.40 \%\end{array}$ \\
\hline May & $\begin{array}{c}4 \\
6.70 \%\end{array}$ & $\begin{array}{c}14 \\
12.70 \% \\
\end{array}$ & $\begin{array}{c}59 \\
21.60 \% \\
\end{array}$ & $\begin{array}{c}29 \\
20.30 \%\end{array}$ & $\begin{array}{c}11 \\
14.70 \%\end{array}$ & $\begin{array}{c}20 \\
18.20 \%\end{array}$ & $\begin{array}{c}137 \\
17.80 \% \\
\end{array}$ \\
\hline June & $\begin{array}{c}6 \\
10.00 \%\end{array}$ & $\begin{array}{c}12 \\
10.90 \%\end{array}$ & $\begin{array}{c}37 \\
13.60 \%\end{array}$ & $\begin{array}{c}19 \\
13.30 \%\end{array}$ & $\begin{array}{c}20 \\
26.70 \%\end{array}$ & $\begin{array}{c}16 \\
14.50 \%\end{array}$ & $\begin{array}{c}110 \\
14.30 \%\end{array}$ \\
\hline July & $\begin{array}{c}24 \\
40.00 \%\end{array}$ & $\begin{array}{c}22 \\
20.00 \%\end{array}$ & $\begin{array}{c}47 \\
17.20 \%\end{array}$ & $\begin{array}{c}34 \\
23.80 \%\end{array}$ & $\begin{array}{c}22 \\
29.30 \%\end{array}$ & $\begin{array}{c}30 \\
27.30 \%\end{array}$ & $\begin{array}{c}179 \\
23.20 \%\end{array}$ \\
\hline
\end{tabular}

\section{Discussion}

During this Covid-19 pandemic, a significant decline in both the elective and emergency cases have been reported in our study. As the first wave of the pandemic hit the world, elective surgical practices were restricted worldwide. The American College of Surgeons recommended to postpone or cancel all elective surgeries in March 2020 [6]. Similarly, National Health Service (NHS) hospitals were advised to postpone elective surgeries for three months to increase the hospital's capacity for the care of Covid positive patients [7]. It was advised by The Royal College to manage emergency surgical cases like acute appendicitis and acute cholecystitis conservatively where possible [8]. While the procedure continued to take place at our hospital setting, there was no statistical difference observed in appendectomies before and during the pandemic ( $p>0.05)$. Rait, et al. [9] reported an $86 \%$ decrease in cases of emergency surgery compared to the months before the quarantine, and the most frequently performed surgical procedure was appendectomy [9]. Richmond BK, et al. [10] demonstrated in their study that the Covid-19 pandemic has had a massive impact on the surgical practice and on the well-being of surgeons in the South Eastern surgical congress, with surgeons reporting cancellation rate of elective surgery around $98.5 \%$ [10]. To avoid the spread of this disease among surgeons and patients, out-patient's clinics were also suspended, adding up to the decline in surgical procedures performed. Spinelli, et al. [11].

Noted that most outpatient clinics were suspended in Italy and scheduled patients were asked not to come to the hospital, and their visits were postponed if they had fever, cough, or any contact history with the Covid positive patient in the last two weeks [11]. Even during the pandemic, trauma incidences are inevitable [12]. In our study, greater proportion of trauma laparotomies were observed during the covid state $(9.7 \%)$ as compared to pre-covid period (5.3\%), and the difference was statistically significant, possibly owing to the decrease in number of non-traumatic surgeries during the pandemic This is likely due to non-presentation or delay in presentation of non-traumatic cases during the lockdown state, In this pandemic, surgeons aim to provide timely surgical care to their patients presenting with emergency surgical conditions along with optimal use of resources, e.g., hospital and intensive care unit beds, Personal protective equipment (PPE), ventilators, and preserving the health of caregivers. Surgeons should use their sound judgment while addressing acute surgical conditions. Many infections and abscesses, which are small, can be treated using local anesthesia in the office, without using the operation theatre facilities. Serious 
acute surgical issues, e.g., perforated viscus or gut ischemia, however, must undergo emergent surgery [13].

The oncological surgeries carried out as per our survey were significantly reduced in the Covid state (340 vs 57 , Pre-Covid vs Covid). There could be several reasons for this huge difference including lockdown, closed outpatient facility, a limited number of admissions, or patients' fear of acquiring Covid from hospitals during the pandemic. Similar findings have been observed globally. Greenwood reports that in England in May 2020,-37\% patients had their oncological treatment started when compared to May 2019 [14]. Oncological procedures, however, shall always be a priority and efforts shall be made to offer better healthcare to the cancer patients. Standard guidelines shall be established regarding the Oncological Surgeries and surgeons shall be made aware of them. Sud, et al. [15] state that delay in surgery in cancer patients could result in increased mortality, and any blockage in the pathway of management of these patients should be removed, and these cases should be managed in the same way as before this Covid pandemic [15].

\section{Conclusion}

Covid-19 pandemic is a threat to every aspect of patient management. Surgical treatment is also affected by this pandemic. Both elective and emergency surgeries are significantly reduced in number including oncological surgeries. However, cancer patients cannot wait, and they must be treated with priority even during the Covid pandemic. A strategy should be made to prevent the overburden we will face once this pandemic is over.

\section{Conflict of Interest}

Authors have no conflict of interest to declare.

\section{Disclosure}

None.

\section{Funding}

None.

\section{Ethical Approval}

Institutional Review Board (IRB) of Dow University of Health Sciences (DUHS).

\section{Authors' Contribution}

- AS: Study conception, writing of article, critical review, revision.
- MA: Study conception, literature review, writing of article, critical review, revision.

- AZ: Data analysis, writing of article.

- SS: Data collection, literature review, writing of article.

- MR: Data collection, literature review, writing of article.

- SS: Critical review, revision, writing of article.

\section{References}

1. (2020) World Health Organization. Coronavirus disease 2019 ('COVID19):" Situation report, 94. World Health Organization.

2. (2020) Eurosurveillance Editorial Team. Note from the editors: World Health Organization declares novel coronavirus (2019-nCoV) sixth public health emergency of international concern. Euro surveillance. 25(5): 200131e

3. Waris A, Khan AU, Ali M, Ali A, Baset A (2020) COVID-19 outbreak: current scenario of Pakistan. New Microbes and New Infections 14: 100681.

4. Ghebreyesus TA (2020) WHO Director-General's opening remarks at the media briefing on COVID-19-11 March 2020. World Health Organization.

5. Nicola M, Alsafi Z, Sohrabi C, Kerwan A, Al Jabir A, et al. (2020) The socioeconomic implications of the coronavirus and COVID-19 pandemic: A review. International Journal of Surgery 78: 185-193.

6. American College of Surgeons (ACS). COVID-19 update: Guidance for triage of non-emergent surgical procedures.

7. Iacobucci G (2020) Covid-19: All non-urgent elective surgery is suspended for at least three months in England. BMJ: British Medical Journal 368: m1106.

8. Anderson I, Fearnhead N, Toogood G. Updated Intercollegiate General Surgery Guidance on COVID 19.

9. Rait JS, Balakumar C, Montauban P, Zarsadias P, Iqbal S, et al. (2020) COVID-19 and surgery: Running on good will or guilt? Annals of Medicine and Surgery 55: 69.

10. Richmond BK, Dean LS, Farrell TM (2020) The Impact of the COVID-19 Pandemic on Surgical Practice in the Southeastern United States: Results of a Survey of the Membership of the Southeastern Surgical Congress. The American surgeon 86(8): 916-925.

11. Spinelli A, Pellino G (2020) COVID-19 pandemic: Perspectives on an unfolding crisis. The British journal of surgery 107(7): 785-787.

12. American College of Surgeons Committee on Trauma. Maintaining trauma center access and care during the COVID-19 pandemic: Guidance document for trauma directors.

13. Cheeyandira A (2020) The effects of COVID-19 pandemic on the provision of urgent surgery: a perspective from the USA. Journal of Surgical Case Reports 2020(4): rjaa109.

14. Greenwood E, Swanton C (2020) Consequences of COVID-19 for cancer care-a CRUK perspective. Nature Reviews Clinical Oncology 23: 1-2.

15. Sud A, Jones M, Broggio J, Loveday C, Torr B, et al. (2020) Collateral damage: The impact on outcomes from cancer surgery of the COVID-19 pandemic. Annals of Oncology 31(8): 1065-1074. 
ISSN: 2574-1241

DOI: 10.26717/BJSTR.2021.35.005727

Amara Zafar. Biomed J Sci \& Tech Res

(i) This work is licensed under Creative Commons Attribution 4.0 License

Submission Link: https://biomedres.us/submit-manuscript.php

$\begin{array}{ll}\text { BIOMEDICAL } & \text { Assets of Publishing with us } \\ \text { RESEARCHES } & \text { Global archiving of articles } \\ \text { - Immediate, unrestricted online access } & \text { - Rigorous Peer Review Process } \\ & \text { - Authors Retain Copyrights } \\ & \end{array}$

